\title{
Urbanization and Public Policy Research: How Should Local Think Tanks Act?
}

\author{
Lingling Peng \\ Department of Social Work, Guangdong Pharmaceutical University, Guangzhou, China \\ Email: 404738865@qq.com
}

How to cite this paper: Peng, L.L. (2019) Urbanization and Public Policy Research: How Should Local Think Tanks Act? Open Journal of Social Sciences, 7, 361-367. https://doi.org/10.4236/jss.2019.77030

Received: May 5, 2019

Accepted: July 27, 2019

Published: July 30, 2019

Copyright ( 2019 by author(s) and Scientific Research Publishing Inc. This work is licensed under the Creative Commons Attribution International License (CC BY 4.0).

http://creativecommons.org/licenses/by/4.0/

\begin{abstract}
Public policy is the main force driving the process of urbanization. This article focuses on two particular issues: First, what is the fundamental qualification of local think tanks (LTTs) that purport to deliver public policy consultancy? Second, at the different stages of urbanization, which kinds of differentiation policies should the government make? What are the added values of LTTs in the process of policymaking? Which kind of policies should LTTs focus on? Which specific channels should LTTs select to effectively communicate with public agencies?
\end{abstract}

\section{Keywords \\ Local Think Tanks}

\section{Public Policies in the Process of Urbanization}

Urbanization is a complex process involving economic, societal, environmental and cultural issues and requires mutual coordination. It is crucial to ensure that there is coordination among various policies as coordination is the prerequisite for a harmonious policy system and, eventually, a smooth urbanization process [1]. It is important to recognize that the process of urbanization ends traditional rural life styles, which have been characterized as scattered and decentralized [2]. This transformation leads to an increasing number of rural residents moving into urban areas. With the expanding size of cities, the collective provision of public services has been the dominant approach for providing basic necessities. Against this background, public policies associated with the development of public services have been increasingly important. Utilizing limited resources to provide a wide range of economic and quality-guaranteed public services has become an important research question that deserves further exploration. For instance, how can we effectively manage public enterprises? How can we imple- 
ment strict monitoring of the costs and prices of public enterprises? How can we ensure that public enterprises provide services in an effective and a clean way? All of these questions must be prioritized in the research agenda. In the process of pursuing this objective, every researcher in the field of socio-economic policy assumes important responsibilities in performing systematic research on those questions identified above, a process in which researchers need to comprehensively communicate with the public.

\section{Approaches through Which LTTs Influence Public Policy}

There are three major approaches through which LTTs can influence the process of urbanization: how policy is made, policy implementation, and the evaluation of policy effects.

\subsection{Influence of LTTs on Policymaking in the Process of Urbanization}

First, LTTs can provide policy alternatives. The impact of LTTs on the inner layers of political power represents the most effective and direct approach through which think tanks can contribute [3]. Typically, through both formal and informal communication channels with leadership and public agencies at every level, LTTs can provide policy alternatives and proposals for decision-makers and lobby them to adopt their proposals and thereby makes those suggestions reality. For a government, a collection of different proposals provided by multiple LTTs offers an excellent opportunity for alternative selection [4]. LTTs provide different policy alternatives for different situations of a certain problem, and this process makes it possible for policymakers to draw comparisons and make decisions. Thus, the principal objective of LTTs is to provide a channel of policy expertise that can provide policy alternatives for the government and eventually have an impact on decision-makers.

Second, LTTs can get involved in decision-making. As a type of non-profit and non-partisan organizations, the most important objective of LTTs is to influence public opinion and public policy [5]. Their involvement in the process of policy-making can typically result in policies that are grounded in public opinion and are more persuasive, which is conducive to improving the image of local government. The process of policymaking can be divided into a multitude of stages, which are described below.

First is the agenda-setting stage. In this stage, LTTs provide policy proposals based on their research outcomes and ensure those proposals become the top alternative for decision-makers and therefore are incorporated into policy agendas [6]. Experts can issue warnings to emerging problems for policymakers and provide guidelines on how policies should be adjusted for policymakers. Currently, expert opinion can guide public opinion via mass media, which, on the one hand, can bring certain policy problems to the attention of the public, changing their interests and values. On the other hand, adopting effective public education makes it possible to form a favorable atmosphere for the adoption of their pro- 
posals. In addition to their direct input into the process of decision-making, LTTs can indirectly influence policymaking through their long-term research and the resulting theoretical framework or paradigm of decision-making, which may serve to formulate a favorable policy atmosphere.

Second is the formulation of policies stage. At this stage, policymakers need to have repeated discussions, and elite groups of public officials begin expressing their preferences [7]. The opinions of experts can function as a catalyst and provide theoretical support for the proposals of policy-makers, which are now well-established.

In the process of decision-making, policy research is crucial for the implementation of policies and regulations. At this stage, policy research can help provide necessary solutions for the problems that may occur during decision-making and provide guidelines on policy evaluation that can serve as a reference for decision-makers in subsequent steps.

Third is the providing specific policy suggestions stage. Because of their expertise, LTTs may have unique insights into the process of decision-making, and therefore, they have creative capacities and can optimize different strategic objectives of policies. The main way for LTTs to provide policy suggestions is by putting forward special research reports directed at the problems of urbanization. These reports can take a variety of forms, which may involve the following: investigative reports, policy advice reports, strategic decision-making advice, and policy framework design reports, among others. The goal of these reports is to provide decision-makers with scientific information to help them make objective decisions.

\subsection{Influence of LTTs on Policy Implementation in the Process of Urbanization}

Policy implementation is not only a dynamic process but also a complex process containing the establishment of executers, use of policy resources, explanation of policy content, initiation of political mobilization and specific implementation and coordination of policy activities. In this process, each element is interlocking, mutually influential and restrained. Policy implementation is a fundamental linkage for solving policy problems. Policy implementation activities include policy advocacy, policy decomposition, material preparation, organization, policy experiment, comprehensive implementation, coordination, monitoring and so on.

First, owing to the independence of think tanks relative to government, they can receive more public trust and recognition in the process of policy advertisement. Thus, LTTs can play a more effective role than the government in influencing public opinion. In the process of policy advocacy, LTTs have more channels in shaping public opinion, such as the timely publication of white papers, releasing research reports, publishing relevant comments, advocating for ideas and providing policy advice through the internet, providing comments via mass media and attending hearings organized by government departments. 
Second, in the process of preparing plans, LTTs can often provide policymakers with professional suggestions through which think tanks can support a change to a specific guideline for an activity. Taking into account the potential problems that may exist in a policy after implementation of the program, as well as the analysis of potential problems, the corresponding preventive measures can be prepared.

Third, most think tank members have rich experience and profound knowledge and are experts on problems in a certain field. Think tank members can take advantage of their theoretical and professional knowledge and conduct meticulous research on the scientific nature and feasibility of the decision. The members can design experimental programs that can be compared under the same conditions to draw a scientific conclusion.

\subsection{Influence of LTTs on Policy Evaluation in the Process of Urbanization}

Through the inspection of the policy plan, LTTs can evaluate the policy process and measure the pros and cons of the policy. Through constantly seeking and locating problems with public policies, LTTs can put forward specific proposals to solve those problems, improve the policy implementation strategy, optimize the policy implementation process, and strengthen the government's capacity to implement its policy [8].

LTTs' study and timely diagnosis of social problems has had a positive significance. First of all, the process of policy evaluation is actually a process of theoretical research, which has high expectation on the theoretical accomplishment of experts. Only through selecting appropriate personnel can the requirements of an assessment be met. LTTs' experts have performed a great deal of research, and they have developed rich professional knowledge and experience in policy, and therefore, they represent an ideal source of participants in this process. Second, as an independent third party, LTTs can perform an extensive evaluation of a policy in an objective and fair manner. Their involvement can overcome the limits of a policy, which have typically been made by a minority of actors in the past. Third, the involvement of LTTs in subsequent revisions of a policy is conducive to resolving conflicts among policy stakeholders, which reflects the spirit of impartiality. Overall, the participation of scholars and experts in public policy evaluation is consistent with the principles of fairness and democracy, which is conducive to promoting scientific and democratic policymaking.

\section{How to Construct a System through Which LTTs Can Meet the Policy Requirements of Urbanization}

\subsection{Why Do We Establish LTTs: How Are the Functions of LTTs Determined?}

To build a new style of LTTs that have Chinese characteristics and meet the de- 
mand under the new normal transformation in the process of urbanization, the construction of an LTT system must take multiple objectives into account. We need to promote high-quality research on practical problems of local government in the processes of urbanization and improving government decision-making [9]. The goals of LTTs should be identified as follows: to provide policy advice on significant and practical problems in the process of urbanization, to strive for the right of free speech and influence in key areas, and to become professional and socially respected think tanks that the government can depend on.

\subsection{How to Establish LTTs: How Can Resources for Constructing a Local Intelligence System Be Accessed?}

First, a diversified human resources system must be constructed. The members of the domestic LTTs are mainly experts from government-affiliated research institutes and colleges; they focus on popular research topics and therefore lack a comprehensive ability to integrate a variety of disciplines [10]. This singular knowledge background can only guarantee professional policy advice, but it is difficult to ensure whether the proposals can be implemented in reality because these researchers do not have real experience of working in government departments. Therefore it is difficult for them to grasp the needs of decision-makers. On the other hand, constrained by a disciplinary background, some experts may not be able to develop a broad and long-term vision. Indeed, the reason why policy consultation provided by senior think tanks in the US has been able to garner the attention of the government lies in their outstanding ability to integrate internal staff with those who have a multidisciplinary background, which in turn, results in the flexibility of the transition between the officials and the public as well as the integration of both parties.

Second, the diversification of research funding for LTTs must be ensured. In the US, the research funding of think tanks has largely been sponsored by a variety of social organizations or enterprises. This institutional arrangement also guarantees that donors can obtain substantive returns from other aspects of society. Thus, in those well-developed markets of policy analysis, such as the US, research funding not only comes from the government but also stems from research scholarships and collective and individual donors. Therefore, China should allot specialized intelligence research funds and through an institutional arrangement encourage donations by social organizations or individuals, which can provide a variety of financial channels for the development of think tanks.

\subsection{How to Establish Think Tanks: How Should the Mechanisms for Constructing a System of LTTs Be Designed?}

It is crucial to create a new nuclear intelligence system that can be labeled as one core with four tanks. One core refers to the local government's decision-making advisory committee and the Office (generally located in the Municipal Policy Research Office), which represents the central link of the local government think 
tank system [11]. To improve the organization level of LTTs and enhance the integration of various types of research resources, local governments can undertake a top-level design. First is professionalization: it is necessary to ensure that the major leadership of the Chinese People's Political Consultative Conference will serve as the leaders of the decision-making advisory committee; bridging the two systems can mobilize the necessary resources. Second is integration, which refers to the integration of the decision-making advisory committee office and the Municipal Policy Research Office in the hope of improving the accuracy of research. Third is substantiation, wherein a decision-making consultation office is established at the city level and carries out the duties of the decision-making advisory committee and the Office, which can improve the efficiency of organization. The four tanks are government think tanks, think tanks in higher education, public think tanks, and enterprise think tanks. These are the four branch networks of LTTs, with each having a central node: this node becomes the main starting point for the construction of the system and maximizes the integration of intellectual resources scattered in various fields.

\section{Conflicts of Interest}

The author declares no conflicts of interest regarding the publication of this paper.

\section{References}

[1] Yu, J. and He, Z. (2010) Entering into the Era of Social Policy: From Developmentalism to the Construction of Social Development Policy System. Social Sciences, 7, 19-26.

[2] CPC Central Committee Writing Group (2013) The Decision of the Central Committee of the Communist Party of China on Comprehensively Deepening Reforms on Several Major Issues. People's Publishing House, Beijing.

[3] Wang, J. (2015) On Situation, Problems and Reform Priorities of the Development of Chinese Think Tanks. Journal of Xinjiang Normal University (Philosophy and Social Sciences Edition), 5, 29-34.

[4] Wu, J. (2011) The Function and Realization Obstacles of Folk Think Tanks in Public Policy Formulation. Journal of North China Electric Power University (Social Science Edition), 9, 41-42.

[5] Liang, P. and Chen, K. (2016) Analysis of the Role and Constraints of Folk Think Tanks in Public Policy Formulation. Economic and Social Development, 11, 46-50.

[6] Xue, L. and Zhu, X. (2009) The Social Function of the Chinese Think Tank-The Road of Reform Centered on the Policy Process. Management World, 10, 55-65.

[7] Ritchie, A. (2010) Think Tank, Political Policy of Public Policy and Expert Policy. Pan Yuhui, Translated, Shanghai Academy of Social Sciences Press, Shanghai.

[8] Wang, Y. and Zhu, Y. (2016) Construction of a New Type of Think Tank with Chinese Characteristics Based on the Relationship Between Knowledge and Power. $E_{X-}$ ploration, 12, 178-184.

[9] He, R.S. (2016) The Realistic Path to Promote the Construction of the Theoretical Think Tank of Socialism with Chinese Characteristics. Journal of Southwest Uni- 
versity (Social Science Edition), 12, 29-34.

[10] Liu, G.Q. and Wu, W. (2013) Suggestions on Building a World-Class Think Tank with Chinese Characteristics. Development Research, 3, 91-93.

[11] Wu, L. and Wang, W.Q. (2013) Logic Analysis of the Construction of Think Tanks in Local Universities-Based on the Innovation of Local Government Governance Models. Education Research of Tsinghua University, 6, 109-114. 